\title{
EVALUATION OF THE NIID-H CERTIFICATION PROGRAM Division of Safety Research Testing and Certification Branch
}

U. S. DEPARTMENT OF HEALTH, EDUCATION, AND WELFARE

Public Health Service

Center for Disease Control

National Institute for Occupational Safety and Health 

EVALUATION OF THE NIOSH CERTIFICATION PROGRAM

DIVISION OF SAFETY RESEARCH

TESTING AND CERTIFICATION BRANCH

REPORT BY CONSULTANTS

\author{
RICHARD BRIEF \\ MORTON CORN \\ ROBERT FIRENZE \\ MARY-WIN O'BRIEN \\ DAVID SCOTT
}

November 21, 1979 
DHEW (NIOSH) Publication No. 80-113 
The National Institute for Occupational Safety and Health (NIOSH), in partial fulfillment of its responsibility for protecting the worker, has established a program activity for personal protective equipment (PPE) and hazard measuring instruments (HMI) evaluation and certification within its Division of Safety Research (DSR).

As a result of increased public concern, particularly with respiratory protective equipment failures, Dr. Anthony Robbins, Director of NIOSH, solicited the opinions of several consultants from various disciplines to provide an external evaluation of the present testing and certification function and to recommend alternative courses of action NIOSH might adopt to execute its mandate more effectively.

The consultants made an initial two-day site visit to the Morgantown Laboratory to obtain a first-hand and consistent understanding of the functional aspects of each Testing and Certification Branch (TCB) program. From the site visit, a work plan was developed and each consultant proceeded, independently, to analyze regulations, technical reports, and program strategies that described the functions of the present TCB program. The analyses led to a consensus that there should be a consistent approach by the consultants for presentation of an objective and relevant analysis of the current TCB program, including identification of the most pressing issues of concern, and recommendations for future action by NIOSH. This interim report is a compendium of results of the individual consultant's investigations of the components of a satisfactory PPE and HMI assurance program, including recommendations to NIOSH for its role in such a program.

The major conclusions in the report are:

1. NIOSH should play an important role in assuring the public of the reliability of personal protective equipment (PPE) and hazard measuring instruments (HMI).

2. NIOSH must assume the major responsibility for providing the public with information related to PPE and HMI performance and usage.

3. The uncertainty about NIOSH's statutory authority to establish a voluntary or mandatory certification program intimates that the agency needs to substantiate the need for the program, not just in terms of equipment-related failures and injuries, but also in terms of how it is to be structured.

4. The DSR Certification procedures represent an amalgamation of regulatory standards, check lists, audits, bench tests, and test protocols that are product and manufacturer oriented 
rather than user oriented. They need to be replaced by a conceptually conceived system that places product performance as the sole responsibility of the manufacturer. The responsibility of NIOSH in this system should be to develop basic performance criteria required for NIOSH certification and to assure adherence of products in usage to these criteria.

The Consultants' recommendations to NIOSH were:

1. The Director of NIOSH should hold a public meeting to solicit views on current testing and certification procedures, and proposals for future procedures as represented in this report.

2. NIOSH, from the Institute Director's Office, should formulate policy positions that define NIOSH's posture on the Testing and Certification program. These policies should reflect the assignment of responsibilities proposed in this report.

3. NIOSH should develop a Division of Safety Research program that focuses on TCB areas of responsibilities, and the components of such a program are identified in this report. This should include a compendium of policies, program objectives and activities, responsibilities, and test protocols.

4. A major addition to the Testing and Certification program should be the development of an information feedback system of product failures and near-failures and an information distribution system that will provide users, potential users, and manufacturers with product performance data. 
Section

I. INTRODUCTION 1

II. INVESTIGATION OF LEGAL AUTHORITY 3

Summary 3

Discussion $\quad 4$

III. ANALYSIS OF THE CURRENT NIOSH TESTING AND 15 CERTIFICATION PROGRAM

$\begin{array}{ll}\text { Certification Procedures } & 15\end{array}$

Conclusions that Relate to Current NIOSH Testing 18 and Certification Procedures

IV. ATTRIBUTES OF A SATISFACTORY ASSURANCE PROGRAM 20 FOR PERSONAL PROTECTIVE EQUIPMENT AND HAZARD MEASURING INSTRUMENTS

Responsibility for Performance of PPE and HMI 21

Responsibility for Assuring That Manufacturers 21

Have Adhered to NIOSH Performance Standards 22

Responsibility for Distribution of Results 22

of NIOSH Sample Testing of PPE and HMI

Responsibility for Establishment of Performance 22

Criteria

Responsibility for Action to Curtail Sales of 22

Defective PPE and HMI

Responsibility for Establishing a Communications 22

Network that Reflects User Experience with

PPE and HMI

Research on Instrumentation for PPE and HMI 23

V. A PROPOSED NIOSH PROGRAM FOR PPE AND HMI TESTING 24 AND CERTIFICATION

Institute and Divisional Responsibilities 24

Legal Basis for Extension of Testing and 25

Certification Beyond Specifically Mandated

Programs

Authorization of Private Laboratories to Test 26

and Certify

Performance Criteria and Standards Development 26

Pre-manufacturing Notification Procedures 26

Quality Assurance 28

$\begin{array}{ll}\text { Research } & 28\end{array}$

PPE and HMI Field Surveillance System 30 
VI. RECOMMENDED NIOSH ACTIONS

31

APPENDICES

APPENDIX A THE CONSUMER PRODUCT SAFETY ACT

33

(15 U.S.C. 2063, 2064, 2065)

APPENDIX B SUGGESTED ANNOUNCEMENT FOR SOLICITATION OF

39

PUBLIC VIEWS ON THE NIOSH ROLE IN TESTING

AND CERTIFICATION OF PPE \& HMI

APPENDIX C CONSULTANT RESOURCES

43

APPENDIX D THE CONSULTANTS

44 


\section{SECTION I}

\section{INTRODUCTION}

The National Institute for Occupational Safety and Health (NIOSH), in partial fulfillment of its responsibility for protecting the worker, has established a program activity for personal protective equipment (PPE) evaluation and certification within its Division of Safety Research (DSR). In the process of formulating a strategic plan for accomplishing the long-range objectives of assuring the public of the reliability and availability of PPE, NIOSH has included a review of the Testing and Certification Branch (TCB) in DSR, which is the focal point for personal protective equipment and hazard measuring instruments (HMI) evaluation and certification.

The Testing and Certification Branch exists within the recently created Division of Safety Research and issues or reinstates about 132 certifications each year for six different types of hazard measuring instruments and personal protective equipment. These presently include three types of respirators, coal mine dust samplers, sound level meters and gas detection indicator tubes. The projection is that the number of devices requiring certification would increase by approximately ten per year so that by 1985 there would be about 56 types of devices which would require certification and that as many as 930 certifications and recertifications would be required. The current level of resources assigned to the group (TCB) is probably not adequate to meet this demand. In addition, the recent events surrounding the failure of a certified device to protect firemen in Lubbock, Texas (see report dated June, 1979, "Tests of Self-Contained Breathing Apparatus Received for Lubbock, Texas, Fire Department") and the follow-up stop-sale order have prompted a critical review of the testing and certification process.

As a result of increased public concern, particularly with respiratory protective equipment failures, $\mathrm{Dr}$. Anthony Robbins, Director of NIOSH, solicited the opinions of several consultants from various disciplines to provide an external evaluation of the present testing and certification function and to recommend alternative courses of action NIOSH might adopt to execute its mandate more effectively. By extending such a broad charge to the consultants, Dr. Robbins gave them the opportunity to examine the entire testing and certification procedure, including: the question of whether the legislation under which TCB operates is adequate or whether any kinds of changes ought to be recommended; an investigation of the nature of the work of the TCB and how it is performed in cooperation with the regulatory agencies [the Occupational Safety and Health Administration (OSHA) and the Mine Safety and Health Administration (MSHA)] as well as with the United States Fire Administration; a review of the research that is conducted by the TCB; and an investigation of the specifics of the surveillance and regulatory approval program now being conducted by the TCB. The specific charge to the consultants from the Director of NIOSH was 
that all options should be studied to assure that the TCB would conduct its program in an efficient and creative manner to maximize protection of workers.

To assist in developing an in-depth understanding of the TCB programs, within the Division of Safety Research, the consultants made an initial two-day site visit to the Morgantown Laboratory in July, 1979. We particularly wanted to obtain a first-hand and consistent understanding of the functional aspects of each TCB Section; therefore, the visit included detailed interviews with the Division Director, the Testing and Certification Branch Chief, each Section Chief, and representatives from the Cincinnati-NIOSH Laboratory respirator research section. (See Appendix C)

From the site visit we developed a work plan and each consultant proceeded, independently, to analyze regulations, technical reports, and program strategies that described the functions of the present TCB program. In addition, we agreed to identify specific technical issues of concern to each of us. A second meeting was held in August to review each of the consultant's progress, discuss mutual concerns, and to define the specific area of study each consultant would pursue independently.

The consensus by the end of the second meeting was that while each consultant should proceed independently with investigating and reporting of specific issues, there should be a consistent approach for presentation of an objective analysis of the current TCB program, including identifying the most pressing issues of concern and recommending future action by NIOSH. In particular we agreed to approach the problem from the viewpoint of needs for worker protection and to emphasize the role of NIOSH in assuring maximum safety in the workplace rather than to restrict our report to a critique of the present NIOSH program activities and recommendations for improvement.

This report is a compendium of results of the individual consultant's investigations of the components of a satisfactory PPE and HMI assurance program. It also includes recommendations to NIOSH for its role in such a program. 
The uncertainty about NIOSH's statutory authority to establish voluntary or mandatory certification programs intimates that the Agency needs to substantiate the need for the program, not just in terms of equipmentrelated failures and injuries, but also in terms of how it is to be structured, i.e., the use of fees for testing, adequate safeguards for hearings and procedures for prompt withdrawal of a hazardous device from the marketplace. Such justifications have not been forthcoming in any of the material proposed to date.

The Mine Safety and Health Act contains statutory authority for programs requiring NIOSH approval of respirators and respirable dust samplers in underground coal mines. Any expansion of this program to other mines or to other types of equipment would have to be done by MSHA regulations requiring the use of approved devices. Whether NIOSH itself has to approve the equipment or whether NIOSH could delegate this authority to accredited laboratories or even manufacturers under established criteria would depend in part on the degree of control the agency retained, i.e., the less discretion given outside parties, the more likely such a delegation would be supportable under general rule-making authority. NIOSH could, of course, contract out the testing, etc., but still retain final authority to issue the approval.

The Occupational Safety and Health Act does not contain any statutory language requiring NIOSH approval or certification of protective equipment or monitoring devices. However, several provisions of the Act lend support to a role for NIOSH in establishing recommended standards and criteria. In addition, there is no evidence of any successful coordination with OSHA, a problem which has plagued both agencies in the past. Yet in this area, as with other standards, there is no reason to believe that if NIOSH has evidence of the inadequacy of existing OSHA requirements then OSHA will not undertake the appropriate procedures to correct the defects, e.g., by revising the safety shoe or hard hat standards. This approach keeps the research and regulation functions separate but it leaves unresolved the issue of certification unless NIOSH either obtains authority similar to that in the MSH Act or OSHA requires that equipment be NIOSH-approved.

Overall, it seems that NIOSH's approach is like that of OSHA in its early years. The goal seems good and protective of employee health and, therefore, there is less need for specific authority, and rational decisions with minimal administrative proceedings are acceptable. While that may suffice for a program which has little substantive impact on people's lives and interests, it is unrealistic where the program is intended to have some clout. The administrative and judicial requirements 
for any planned government action must be analyzed carefully along with the technical input so that all the strengths and weaknesses are known to the Agency before it acts. The greater the public participation in this process, the sounder the Agency's decision will be.

\section{$\underline{\text { Discussion }}$}

This preliminary report on the NIOSH certification program focuses on the statutory and regulatory framework of the program, the legal liability questions surrounding government certification, and suggested additional or alternative strategies for assuring protection of the user.

\section{A. Introduction}

This section deals with NIOSH's current statutory authority and regulatory implementation of that authority for approval of personal protection equipment and monitoring devices.

There are two statutes that set out NIOSH's responsibility --the Federal Mine Safety and Health Act of 1977 (30 U.S.C. 801) and the Occupational Safety and Health Act of 1970 (29 U.S.C. 651 et seq.). The regulations are set out in various parts of the Code of Federal Regulations.

\section{B. Mine Safety and Health Act}

\section{Statutory Provisions.}

The 1977 Act is the culmination of the efforts to improve the Metal and Non-Metallic Mine Safety Act of 1966 (30 U.S.C. 721) and the Coal Mine Safety and Health Act of 1969 (30 U.S.C. 801) by transferring the program to the Department of Labor and by increasing the protection provided to miners under both Acts. The provisions of the MSH Act that are relevant to the certification program are set out below:

Sec. 202. (a) Respirable Dust Samples: Each operator of a coal mine shall take accurate samples of the amount of respirable dust in the mine atmosphere to which each miner in the active workings of such mine is exposed. Such samples shall be taken by any device approved by the Secretary and the Secretary of Health, Education, and Welfare... (emphasis added) [30 U.S.C. 842(a)].

Sec. 202.(e) References to concentrations of respirable dust in this title mean the 
average concentration of respirable dust measured with a device approved by the Secretary and the Secretary of Health, Education, and Welfare. (emphasis added) [30 U.S.C. 842 (e)].

This section has been implemented by the regulation in 30 CFR Part 74 . That regulation contains requirements for the construction and operation of the sampler unit and authorizes NIOSH to determine whether the sampler units meet the requirements. The Bureau of Mines (now MSHA) is to conduct tests for the pump unit to see that it is intrinsically safe.

Sec. 202.(h) Respiratory Equipment:

Respiratory equipment approved by the Secretary and the Secretary of Health, Education, and Welfare shall be made available to all persons whenever exposed to concentrations of respirable dust in excess of the levels required to be maintained under this Act. (emphasis added) [30 U.S.C. $842(\mathrm{~h})$ ].

Section 204. ...Respiratory equipment approved by the Secretary and the Secretary of Health, Education, and Welfare shall be provided persons exposed for short periods to inhalation hazards from gas, dusts, fumes, or mist..... (30 U.S.C. 844).

These sections provide NIOSH with the authority for the mandatory certification program for respirators in underground coal mines. That authority is implemented through regulations in $30 \mathrm{CFR} 11$ and $30 \mathrm{CFR} 70.300$. The use of Mine Enforcement and Safety Administration (MESA) approved respirators is extended to metal and non-metal mines by 30 CFR 55.5-5(a).

Sec. 206. Noise Standards: On and after the operative date of this title, the standards on noise prescribed under the Walsh-Healey Public Contracts Act, as amended, in effect October 1, 1969, shall be applicable to each coal mine and each operator of such mine shall comply with them. Within six months after the date of enactment of this Act, the Secretary of Health, Education, and Welfare shall establish, and the Secretary shall 
publish, as provided in Section 101 of this Act, proposed mandatory health standards establishing maximum noise exposure levels for all underground coal mines. Beginning six months after the operative date of this title, and at intervals of at least every six months thereafter, the operator of each coal mine shall conduct, in a manner prescribed by the Secretary of Health, Education, and Welfare, tests by a qualified person of the noise level at the mine and report and certify the results to the Secretary and the Secretary of Health, Education, and Welfare. In meeting such standard under this section, the operator shall not require the use of any protective device or system, including personal devices, which the secretary or his authorized representative finds to be hazardous or cause a hazard to the miners in such mine. (emphasis added) (30 U.S.C. 846).

Since 1971, operators of underground coal mines have been required to comply with this section in accordance with $30 \mathrm{CFR}$ Part 70.500 . In 1976, NIOSH finalized a voluntary certification program for sound level meter sets (42 CFR Part 82). This regulation was revoked in 1978 (43 FR 33247, July 31, 1978) in favor of a voluntary one based on guidelines.

The language of this section clearly divides the responsibility between NIOSH and MSHA where NIOSH prescribes the testing method and MSHA has the responsibility for determining whether any protective device or system is a hazard. MSHA could, of course, request NIOSH's assistance in making these determinations. There is no specific authority in this section to approve the testing devices such as sound level meter sets and dosimeters although it seems clear that as part of prescribing the test method, NIOSH could specify that the devices used be approved.

Sec. 501.(a) General Policy:

The Secretary of the Interior and the Secretary of Health, Education, and Welfare, as appropriate, shall conduct such studies, research, experiments, and demonstrations as may be appropriate --

(1) to improve working conditions and practices in coal or other mines, and to prevent accidents and occupational diseases originating in the coal or other mining industry;

(11) to determine upon the written request by any operator or authorized representative of miners, specifying with reasonable particularity the 
grounds upon which such request is made, whether any substance normally found in a coal or other mine has potentially toxic effects in the concentrations normally found in the coal or other mine or whether any physical agents or equipment found or used in a coal or other mine has potentially hazardous effects, and shall submit such determinations to both the operators and miners as soon as possible; and

(12) for such other purposes as they deem necessary to carry out the purposes of this Act. (emphasis added) [30 U.S.C. 951 (a) (1), (11), (12)].

By using this general language authorizing research, studies, experiments and demonstrations, NIOSH may have some flexibility in dealing with evaluation of equipment in use. Of particular importance is paragraph 11 allowing operators and miners to request determinations on the potential hazards of equipment found or us'ed in the mine. This language can be read to include more than operating equipment and to permit evaluation of protective equipment and measuring devices.

It should also be noted that paragraph (c) of that same Section 501 [30 U.S.C. 951(c)] requires that the "information, uses, products, processes, patents, and other developments" resulting from the research be available to the public unless the government limits access in the public interest. In addition, in implementing Section 501, NIOSH would work with the Department of Interior, not the Labor Department.

Sec. 501.(g) Development of Respirators:

The Secretary of Health, Education, and

Welfare is authorized to make grants to any

public or private agency, institution, or

organization, and operators or individuals

for research and experiments to develop

effective respiratory equipment. (emphasis

added) [30 U.S.C. 951(g)].

The utility of this section is obvious if the projects are selected carefully and the funding is adequate.

Sec. 508. General Rulemaking:

The Secretary, the Secretary of Health, Education, and Welfare, and the Panel are authorized to issue such regulations as each deems appropriate to carry out any provision of this Act. (30 U.S.C. 957).

This is the usual grant of authority to issue regulations to implement specific provisions of a law. 


\section{Regulatory Provisions.}

The basic regulatory provisions implementing the NIOSH program under the MSH Act are set out above under the individual statutory.

3. Summary.

The MSH Act contains statutory authority for programs requiring NIOSH approval of respirators and respirable dust samplers in underground coal mines. Any expansion of this program to other mines or to other types of equipment would have to be done by MSHA regulations requiring the use of approved devices. Whether NIOSH itself has to approve the equipment or whether NIOSH could delegate this authority to accredited laboratories or even manufacturers under established criteria would depend in part on the degree of control the agency retained, $i . e .$, the less discretion given outside parties, the more likely such a delegation would be supportable under general rulemaking authority. NIOSH could, of course, contract out the testing, etc., but still retain final authority to issue the approval. An analogous situation occurred in the challenge to OSHA's promulgation of the ground fault circuit interrupter standard 29 CFR 1910.309(c) and $1926.400(\mathrm{~h})$. When the standard was challenged by the National Constructors Association F.2d__ 1978 CCH OSHD 22,826 (D.C. Cir. 1978), one of the issues raised was the legality of the definition of approved GFCI's as those "determined to be safe by a nationally recognized testing laboratory, such as but not limited to, Underwriters' Laboratories, Inc." UL is apparently the only tester of GFCI's and the question was whether the reference to UL was an unlawful delegation of authority. The Court held that since OSHA in its rulemaking had approved UL's current criteria for GFCI's that the standard was valid. The Court did not rule on the question of the legality of OSHA enforcing future changes to UL's criteria without further rulemaking since the Court was not faced with that question. This case also is relevant to the use by OSHA of the phrase "NIOSH approved" in setting its standards. 


\section{Occupational Safety and Health Act}

\section{Statutory Provisions}

The OSH Act does not contain any statutory language requiring NIOSH approval or certification of protective equipment or monitoring devices. However, several provisions of the Act lend support to a role for NIOSH in establishing recommended standards and criteria. For example, Section $20(a)(2)$ states that:

The Secretary of Health, Education, and Welfare shall from time to time consult with the Secretary in order to develop specific plans for such research, demonstrations, and experiments as are necessary to produce criteria, including criteria identifying toxic substances, enabling the Secretary to meet his responsibility for the formulation of safety and health standards under this Act; and the Secretary of Health, Education, and Welfare, on the basis of such research, demonstrations, and experiments and any other information available to him, shall develop and publish at least annually such criteria as will effectuate the purposes of this Act. (emphasis added) (29 U.S.C. 669).

NIOSH relied on the following sections when it proposed its voluntary certification program in 1974 (39 FR 11923 and 22276):

Section 22

(c) The Institute is authorized to...

(1) develop and establish recommended occupational safety and health standards (29 U.S.C. 671).

Section 21

(a) The Secretary of Health, Education, and Welfare, after consultation with the Secretary...shall conduct, directly or by grants or contracts...

(2) informational programs on the importance of and proper use of adequate safety and health equipment (29 U.S.C. 670).

In addition, NIOSH has general rulemaking authority to carry out its responsibilities under the Act [29 U.S.C. $657(\mathrm{~g})(2)$ ] and also has the right to enter workplaces to carry out its responsibilities under the Act [29 U.S.C. 669 (b)]. 
The standards that the criteria and recommendations generally relate to are those set by the Secretary of Labor under Section 6 (b) of the OSH Act (29 U.S.C. 655) and they are defined to include conditions, or the adoption or use of one or more practices, means, methods, operations, or processes, reasonably necessary or appropriate to provide safe and healthful employment and places of employment. Also, as specified under 29 U.S.C. 655 (b) (7), the standards, where appropriate, shall prescribe suitable protective equipment.

\section{Regulatory Provisions}

Apart from the regulations promulgated under the MSH Act referred to above, NIOSH has no current regulations of its own for certification of protective equipment other than respirators. Instead, the Agency's role has been one of responding to those few OSHA regulations requiring NIOSH approved equipment. Some examples include the general requirement in 29 CFR 1910134 (a)(11) for approved or accepted respirators, the vinyl chloride respirators, particularly the end-of-service life indicators (30 CFR 11.20 et seq.), and the approval of respirators for coke oven emissions (gases, vapors, and particulates), which has not yet been accomplished. Other OSHA regulations dealing with protective equipment reference ANSI consensus standards, not NIOSH-approved equipment. See 29 CFR 1910.135 (head protection) and 1910.136 (foot protection).

In 1974, NIOSH embarked on a program of promulgating certification programs for protective equipment and monitoring devices. As stated in the notice of proposed rulemaking and the subsequent notice of hearing (39 FR 22933 and 39 FR 22276), the purpose of the regulations was to recommend safety and health standards by setting out performance and test requirements, quality control, and certification and testing by NIOSH under a fee system. The proposed program ran into a great deal of criticism from manufacturers at a one day hearing in July, 1974. Apart from the comments on the provisions of the proposed requirements, many questions were raised about NIOSH's authority to promulgate these regulations. The basic thrust of the criticism was that NIOSH is the research agency and OSHA is the regulatory body. Therefore, while NIOSH could develop and recommend criteria for approval of equipment to OSHA, only OSHA could require the use of approved equipment. In addition, there were also questions raised as to whether OSHA could establish NIOSH as the sole approval agency and whether OSHA, let alone NIOSH, could certify laboratories. While NIOSH received support from the Industrial Union Department, AFL-CIO and Construction Employers, they did not provide any legal support for the proposal.

In 1978, after withdrawing the proposals referred to above, NIOSH announced its intention to use guidelines and not regulations as an extension of the Agency's authority to recommend standards (43 FR 33247). 


\section{Summary}

The uncertainty about NIOSH's statutory authority to establish certification programs whether voluntary or mandatory intimates that the Agency needs strong proof of the need for the program not just in terms of equipment-related failures and injuries but also in terms of how it is to be structured, i.e., the use of fees for testing, and adequate safeguards for hearings balanced by the need to protect users through prompt withdrawal of a hazardous device. Such justifications have not been forthcoming in any of the material proposed to date.

In addition, there is no evidence of any successful coordination with OSHA, a problem which has plagued both agencies in the past. Yet in this area, as with other standards, there is no reason to believe that if NIOSH has evidence of the inadequacy of existing OSHA requirements then OSHA will not undertake the appropriate procedures to correct the defects, e.g., by revising the safety shoe or hard hat standards. This approach keeps the research and regulation functions separate but it leaves unresolved the issue of certification unless NIOSH either obtains authority similar to that in the MSH Act or OSHA requires that equipment be NIOSH-approved.

Overal1, it seems that NIOSH's approach is like that of OSHA in its early years. The goal seems good and protective of employee health and, therefore, there is less need for specific authority, and rational decisions with minimal administrative proceedings are acceptable. While that may suffice for a program which has little substantive impact on people's lives and interests, it is unrealistic where the program is intended to have some clout. The administrative and judicial requirements for any planned government action must be analyzed carefully along with the technical input so that all the strengths and weaknesses are known to the Agency before it acts. The greater the public participation in this process, the sounder the Agency's decision will be.

\section{Certification and Liability Questions}

Traditionally, the government has been immune to lawsuits by private individuals even where the government has been negligent. This is known as the doctrine of sovereign immunity. However, as to the Federal government. Congress has passed the Federal Torts Claims Act (28 U.S.C. 2671 et seq.). The FTCA is a general waiver of that immunity for negligence with certain exemptions. The waiver of immunity would govern the activity of Federal agencies such as NIOSH, but does not cover contractors who would be liable under normal litigation procedures.

There are two sections of the law that are important to determining the scope of the government's liability in areas such as the certification program. The first is as follows:

The United States shall be liable, respecting the provisions of this title relating to torts 
claims, in the same manner and to the same extent as a private individual under like circumstances ...(28 U.S.C. 2674).

Under the second section which deals with jurisdiction of the court to hear these cases, the liability is defined as limited to "negligent or wrongful acts or omissions" when the employee is acting within the scope of his/her employment [28 U.S.C. $1346(a)$ ].

Because of these two sections, the courts have held that the United States is not liable under theories of absolute liability or liability without fault. There must be a showing of negligence. See Gowdy v. U.S. 412 F.2d 525 (CA 6, 1969) cert den 90 S. Ct. 437 (1969), reh den 90 S. Ct. 750 (1970) and U.S. v. Page 350 F.2d 28 (CA 10, 1965) cert den 86 s. Ct. 552 (1966). Therefore, since the theories of warranty, product liability, and strict liability do not rely on a finding of fault, they are not applicable to determining the government's liability. A finding of negligence is needed.

The FTCA goes on to define what is not negligence as follows:

"(a) Any claim based upon an act or omission of an employee of the Government, exercising due care, in the execution of a statute or regulation, whether or not such statute or regulation be valid, or based upon the exercise or performance or the failure to exercise or perform a discretionary function or duty on the part of a federal agency or an employee of the Government, whether or not the discretion involved be abused." [28 U.S.C. 2680 (a)].

Therefore, if any action of the government employee falls within the terms of this section, the government is protected from liability. of course, there is always the possibility that a given set of facts will not be covered by this exception so that liability will be found. For example, a given set of facts may be actionable if the act or omission occurred in the operational as opposed to the planning phase or if the employee failed to conform to the established regulations. See Driscoll v. U.S. 525 F.2d 136 (CA 9, 1975) and Griffin v. U.S. 500 F.2d 1059 (CA 3, 1974). In general, the granting or revocation of a license and, by analogy a certification, is not actionable absent a showing of negligence. See Coastwise Packet Co.v. U.S. 277 F.Supp. 920 (D.C. Mass. 1968) aff'd 398 F.2d 77 (CA 1, 1968) cert den 89 S. C. 303 (1968). There is also no liability for misrepresentation even if it is negligent. See Fitch V. U.S. 513 F.2d 1013 (CA 6, 1975) cert den 96 S. Ct. 127 (1975).

In short, a certification program run by the government runs fewer risks of successful legal claims being pressed than a system where contractors or manufacturers were required to do the certification. It should be noted that there are a number of legal and policy considerations 
that impact on the extent and nature of the liability of non-governmental certifying organizations, but in general they would be liable not just for negligence but also on liability without fault theories. See Sheldon, A.W. "Tort Liability of Independent Testing Agencies", Materials Research \& Standards MSTRA, Vo1. 9, No. 1, 17-29, 1969, and 56 Cornell Law Review 132 (1970). If recommendations are made for certification outside of NIOSH, then the nature of this liability and any recommendations to either expand or limit it or to provide incentives for the assumption of such liability should be seriously explored. Along those lines, both Congress and the Administration are evaluating various product liability "problems" that have cropped up in the area of industrial accidents. See Draft Product Liability Law, Department of Commerce, January 12, 1979, Federal Register Part VIII and the preceding Options Paper, Federal Register, Thursday, April 6, 1978, Part III.

\section{E. Alternative Strategies}

A cursory review of options and alternatives in the certification field suggested the following areas be explored:

1. The Consumer Product Safety Act (15 U.S.C. 2063) requires product certification and labeling. Under that provision, the manufacturers must certify that the product conforms to all applicable consumer product safety standards and to say which standards apply. A complete copy of the statutory provision is attached. (Appendix A)

2. The CPS Act also authorizes an Injury Information Clearinghouse to collect and disseminate information on the causes and prevention of injuries and illnesses. That same section (15 U.S.C. 2064) authorizes the Commission to test consumer products and develop test methods and testing devices and to assist public and private organizations in the development of standards and test methods.

3. OSHA has a regulation setting out rules of procedure and criteria for accreditation of testing laboratories (29 CFR 1907). However, this regulation has never been implemented. The Department of Commerce also has voluntary accreditation regulations that could be used in the event the certification program is expanded to include outside labs. See 15 CFR Part 7a.

The operation of these options, especially the CPSC system, should be evaluated for its applicability to NIOSH.

In addition to investigating other ways of conducting a certification program, it is also important to review ways of making any such program work for the users. Some of the methods that seem appropriate are more precise decertification procedures, recall and stop sale requirements as well as maintaining lists of, and notification procedures for, users, along with the necessary publicity to make the procedures effective. See 15 U.S.C. 2064 on the repurchase provisions of the CPS Act 
attached. In setting up either mandatory or voluntary certification procedures and performance criteria. NIOSH should incorporate these types of user protection on an official basis as a condition of certification. See Congoleum Industries Inc v. Consumer Product Safety Commission 602 F.2d 220 (CA 9, 1979) holding that the CPSC could not order recall and refunding under the Flammable Fabrics Act because of the lack of specific legislative authority authorizing those remedies. 


\section{Certification Procedures}

The Division of Safety Research certification procedures, as characterized by the TCB program for Self-Contained-Breathing-Apparatus (Respirators), are a series of segmented activities. Viewed collectively, they may give the impression of being a system that utilizes a rigorous analytical (scientific) process for improving and protecting workers' safety and health. Rather, the procedures represent an amalgamation of regulatory standards, check lists, audits, bench tests, and test protocols that are product and manufacturer oriented rather than user oriented. They need to be replaced by a conceptually conceived system that places product performance as the sole responsibility of the manufacturer. The responsibility of $\mathrm{NIOSH}$ in this system should be to develop basic performance criteria required for NIOSH Certification and to assure adherence of products in usage to these criteria.

Under the present TCB procedures, manufacturers submit their products for approval and pay a fee for the government testing and evaluation services which can ultimately lead to product certification. The current procedure evolved over decades in response from NIOSH and predecessor agencies to newly assigned statutory responsibilities and perceived needs for PPE and HMI certification programs. These procedures attempt to meet current, more stringent demands for product reliability and safety. The key question is whether or not the evolved structure and procedures meet today's demands. The procedures include the development of performance criteria, product development, and product quality monitoring, i.e., testing, quality assurance and certification. Figure 1 is a flow diagram for the current NIOSH certification procedure for PPE and HMI.

Performance criteria for PPE and HMI are defined as product specifications for standards to effectively protect workers from occupational injury or illness. The TCB procedures include requirements to meet regulatory standards as defined by the enforcement agencies that NIOSH services, e.g., MSHA, OSHA. On the other hand the standards, in turn, may act as the basis for the development of performance criteria by NIOSH and/or PPE or HMI research by NIOSH. When a new instrument or protective device has been developed and initial certification is being sought by the manufacturer, the product and/or its performance criteria may be identified as the precursor to the standard. This would be an ideal sequence of events and conceptually a superior approach to meeting user needs because the criteria could then be incorporated in recommendations for occupational safety and health.

In any case, many standards do not include well defined performance criteria, especially for HMI; there are no performance criteria for many 


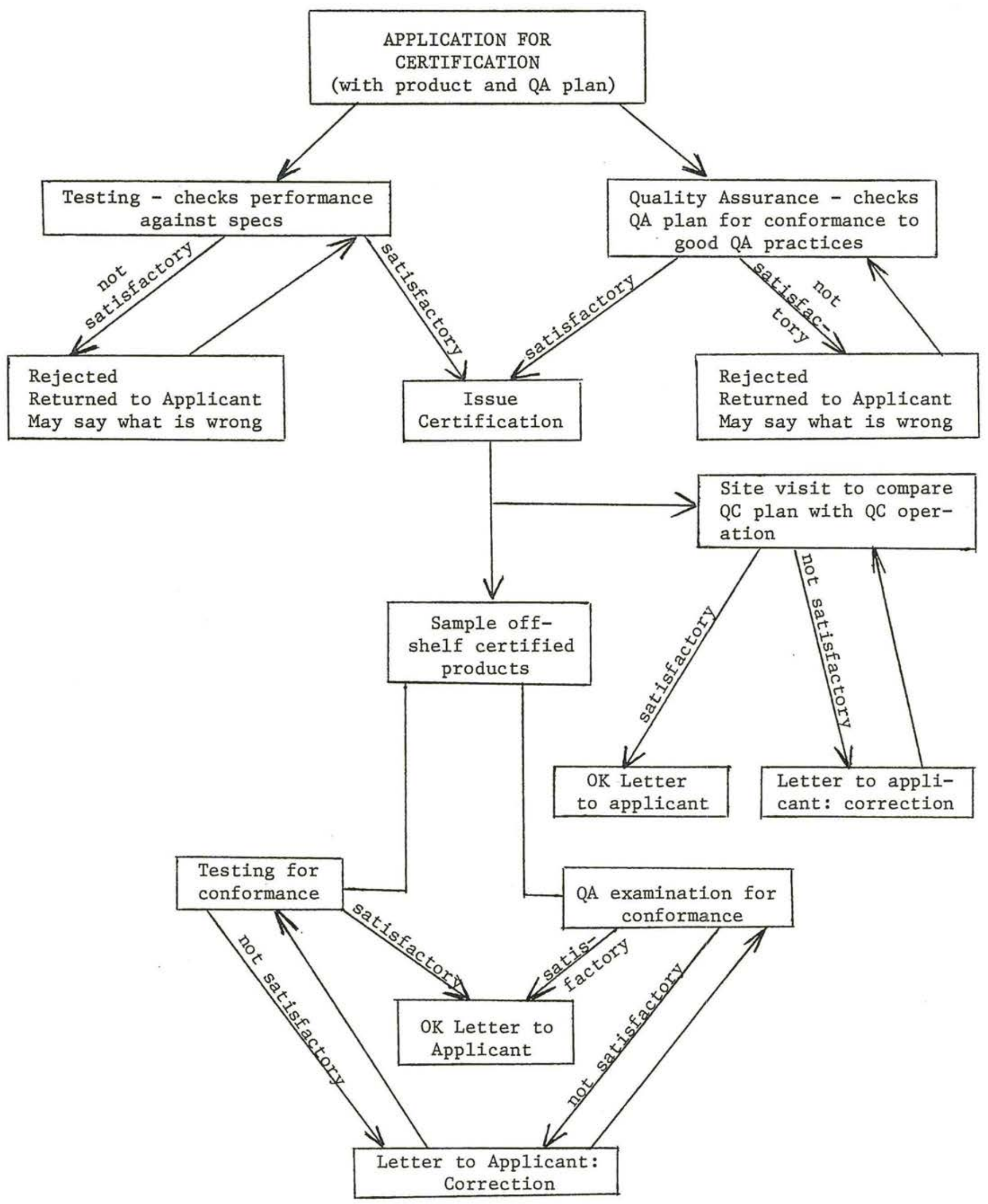

FIGURE 1. NIOSH CERTIFICATION PROCEDURE FOR HMI AND PPE 
HMI. The few consensus standards available for HMI and PPE concentrate on parameters of performance that have little to do with occupational safety and health requirements, especially with regard to reliability and ease of use by the worker. There is a need for improved performance criteria development as one means for providing sensitive, reliable, accurate and precise HMI and reliable PPE to the users. The results of developing such performance criteria will be recommendations for appropriate occupational safety and health standards.

NIOSH testing and analysis has already determined that much of the currently available PPE performance criteria is not based on scientific principles for worker protection. In some cases test protocols attempt to utilize existing American National Standards Institute (ANSI) standards because of their wide acceptance. It is now recognized that they are not adequate for some applications. Alternate test procedures may be more indicative of the actual field situation, i.e., user experience. A necessary first step to improve worker safety and health in the workplace is the development of performance criteria, performance standards, and test procedures that will reflect user experience in the workplace. The present TCB procedures, in many cases, do not include quantifiable criteria or reflect user experience.

Under the present T\&C procedures, manufacturers submit their products for approval and pay a fee for the government service. A complex system of registering device plans and parts with NIOSH has also been developed. Any changes in parts or manufacturing procedures are transmitted to NIOSH for the purpose of registering changes in the NIOSH approved device file. NIOSH quality control consists of the T\&C Lab Quality Assurance Section working with the manufacturer to develop a quality control program. Manufacturers' facilities are visited at currently undefined intervals to sample product quality and to monitor quality control. These visits are more analogous to providing consultation to, rather than auditing, a manufacturing program. It is fair to state that while the current NIOSH quality assurance program offers the manufacturer a high degree of "respectability" if he/she complies with NIOSH suggested procedures, it does not assure the users that devices produced under such a program have a sufficiently high assurance of safety. The recent problems with Scott and SurvivAir units attest to the weaknesses of the current system.

The direct and indirect involvement of the TCB Quality Assurance Section with the manufacturer is unnecessary. The performance of PPE and HMI should be the sole responsibility of the manufacturer and testing and field trial should effectively identify defects and precipitate corrective design or manufacturing actions. More importantly, if the manufacturer clearly understands that regardless of NIOSH certification, he is always solely liable for the consequences of product failure and will be held accountable, the incentive to have rigorous quality assurance and quality control programs will become irresistible. 
Under the present system, NIOSH works closely with the manufacturer from the time certification is granted. This close association with the manufacturer is demonstrated by the TCB monitoring of the manufacturer's programs of quality control, and sampling and testing off-the-lineproducts. This involvement places NIOSH in an awkward position and suggests liability through association if product fallure results in worker injury. Even if NIOSH runs a lesser risk of losing claims brought against it for negligence, its involvement in such claims will do little to increase NIOSH's credibility in the entire area of testing and certification and will lessen user confidence in NIOSH and PPE and HMI.

In conclusion, the TCB Quality Assurance Program should not be involved directly with manufacturers, but should limit its effort to establishing minimum quality assurance and quality control guides that the manufacturer can comply with.

Conclusions that Relate to Current NIOSH Testing and Certification Procedures

During the review process there were conclusions drawn from management and programmatic issues related to current NIOSH testing and certification procedures. They are:

1. The present NIOSH procedures for evaluating and certifying manufacturers' products are severely taxing agency resources. If present operating procedures continue in order to meet future demand for services, expansion of NIOSH resources will be required to perform on a larger scale exactly the same tasks as are now performed. Furthermore, the TCB staff interviewed by us indicated that additional resources will solve program deficiencies, especially those as exemplified by the Scott and SurvivAir PPE failures. We feel it is highly questionable whether program deficiencies can be corrected by this proposed solution to the problem. Therefore, we conclude that this approach should not be further pursued. Rather, in order to fulfill its goal of effectively assuring a high degree of confidence to users of PPE and HMI, NIOSH must alter its present procedures.

2. There is no well defined organizational structure in place within the Division of Safety Research, one that identifies and interprets policy, develops program objectives based on policy, and institutes formal administrative procedures to insure implementation of programs that will meet policy goals and program objectives. The present TCB program appears to be almost totally geared to making adjustments in the existing system, not only as standard operating procedure, but as a way of correcting deficiencies. Furthermore, the interpretation of policy and definition of program objectives takes place at the branch and program levels of management rather than at the Institute and Division levels.

Where policy goals have evolved by one means or another, it is not evident that the Division of Safety Research directs its research programs in an 
effort to meet policy goals. For example, the NIOSH-funded Los Alamos Respirator Studies were conceived to develop analytical laboratory or field test procedures for $\mathrm{PPE}$ and HMI as they relate to recommended standards for OSHA. After years of funding, many results transmitted to NIOSH were characterized by NIOSH staff as inappropriate for certification or field testing of PPE and HMI.

3. The present NIOSH certification procedure, including the fee schedule, is utilized and viewed by manufacturers as part of their quality assurance program to guarantee product effectiveness and operating reliability. This is especially true of relatively small manufacturers who lack formal quality assurance and quality control systems. NIOSH currently lends credibility to manufacturers' products by certification and approval and thus by association with the manufacturer, transfers a high degree of confidence in these devices to users. In some cases, events have demonstrated that this confidence is not well founded.

4. There is no formal mechanism within the Safety Research Division for the user population to communicate failures, defects, or operational difficulties experienced in the workplace to NIOSH. Such a feedback system must be developed by NIOSH.

5. Finally, it is our unanimous opinion that the technical qualifications and task performance of the Testing and Certification Branch staff is satisfactory. The Branch requires definitions of goals, objectives, and function and the associated restructuring and evaluation of performance to meet those goals and objectives. In this way the considerable technical talents now on-board will be mobilized and more efficiently utilized. 


\section{ATTRIBUTES OF A SATISFACTORY ASSURANCE PROGRAM FOR PERSONAL PROTECTIVE EQUIPMENT AND HAZARD MEASURING INSTRUMENTS}

There is consensus among the consultants that NIOSH should play an important role in assuring the public of the reliability and accuracy of hazard measuring instruments and the reliability of personal protective equipment. As indicated in Section III, the current NIOSH programs aimed at improving HMI and PPE are not effectively meeting the needs of the public. There have been several recent indications of the failure of the present NIOSH systems to focus upon PPE in the field which would fail upon emergency usage. There are also indications that the present systems are straining to keep up with demand with current resource allocations of approximately $\$ 1,800,000.00$ and 67 man years of effort during the current fiscal year. However, the efforts of NIOSH should not be undervalued; since 1972 NIOSH has issued over 500 certifications of HMI and PPE, processed nearly 1500 modifications of certifications, and through its quality assurance program attempted to assure conformance of respirators, coal mine dust samplers, sound level meters, and gas and vapor detector tubes to certification requirements. There is long term research being conducted for respiratory product development and respirator performance criteria development and protective clothing. Some work is also aimed at developing performance criteria for standards for HMI and PPE. Other instrument development work involves personal sampling instruments and portable direct reading instruments for monitoring control of work environments and for monitoring the effectiveness of engineering controls. Several products now on the market have been evaluated and results of these evaluations have been published by NIOSH for enlightenment of the public. It is not that these efforts are judged to be inappropriate for NIOSH but, rather, that resources have not been allocated in a manner that will assure the maximum output for public needs. In Section III we indicated the need for definition of goals, policies, and organizational structure in PPE and HMI involvement by NIOSH. We now ask, what are the characteristics of an assurance program, one which reflects current needs rather than needs which may have been in existence when current NIOSH procedures were developed years ago, and how do we identify them?

The basis for identification of the attributes of a PPE and HMI assurance program should be the worker's expectations at the time the product is used in the workplace as derived from certification by NIOSH and from manufacturers' product performance claims. The worker should be able to reasonably expect:

- NIOSH and the manufacturer have carefully considered the product and its intended use and developed performance criteria and standards that assure a high standard of performance in the workplace; 
- Adequate testing has been performed to ensure that product performance is equal to or exceeds the product standard; and

- Independent testing in any qualified laboratory could be performed to verify the product's compliance with the standard.

The following are considered essential assignments of responsibility in a system which effectively utilizes resources devoted to improving PPE and HMI performance in the field.

Responsibility for Performance of PPE and HMI

The responsibility for satisfactory performance of any PPE or HMI is that of the manufacturer. Any product marketed must be backed by those deriving profit from this marketability. NIOSH cannot issue a stamp of approval for any PPE or HMI. NIOSH must guide manufacturers of these types of apparatus and equipment, if, indeed, they are in need of guidance. The stamp of "NIOSH Approved" has implied a sharing of responsibility for performance by the manufacturer and NIOSH. The tests recommended by NIOSH should be substantiated by investigatory programs within NIOSH. The performance of these tests on PPE or HMI in a sufficient number of products to assure a very high level of product quality control is the responsibility of the manufacturer and not of NIOSH.

Responsibility for Assuring That Manufacturers Have Adhered to NIOSH Performance Standards

NIOSH, in order to fulfill its responsibilities to the public to assure a high degree of performance of PPE or HMI purchased on the open market, must undertake some form of sampling program of manufactured products to assure the public that manufacturers are involved in a quality control program which results in a very high degree of confidence in product reliability under conditions products were designed to meet. Thus, NIOSH should be performing the same types of performance tests that manufacturers are performing, but NIOSH should be performing these tests only for the purpose of confirming manufacturers' reliability claims.

The interaction of NIOSH and the manufacturer should be clearly that of a regulator and a regulatee. NIOSH must explicitly state performance criteria and elaborate in detail on the manner in which performance criteria can be tested. They must also teach manufacturers how to perform performance criteria tests, if the manufacturers desire such instruction. NIOSH must perform sufficient investigation to assure manufacturers and the public that their performance criteria and associated tests are the most appropriate for the HMI and PPE undergoing tests. 
Responsibility for Distribution of Results of NIOSH Sample Testing of PPE and HMI

NIOSH must assume the major responsibility for providing the public with information related to PPE and HMI performance and usage. Currently, results of testing are published under NIOSH auspices but publications are highly technical, are not readily understood by non-technical users such as factory workers, and have not received extensive circulation. All users of PPE and HMI must understand the results of testing. NIOSH must recognize that a satisfactory program not only involves testing to confirm or refute manufacturers' claims, but also conveys results of tests to users. The latter involves the distribution of information to the entire U.S. work force.

Responsibility for Establishment of Performance Criteria

The establishment of performance criteria is a major involvement of those charged with developing a satisfactory assurance program. These criteria must be realistic and must be technologically as advanced as the state of the art will permit. Many current NIOSH tests of PPE, in particular, are recognized by manufacturers and researchers in the health and safety field to be lagging in the current state of the art of testing. A satisfactory assurance program must rest on advanced investigatory work by NIOSH. A satisfactory assurance program cannot be one associated with NIOSH performance criteria and tests which are technological anachronisms.

Responsibility for Action to Curtail Sales of Defective PPE and HMI

Upon the gathering of sufficient information which indicates an unsatisfactory product is to be manufactured or is being manufactured, NIOSH must develop mechanisms to assure the curtailment of sales of these devices or recall of those on the market. The mechanisms developed by NIOSH must be sufficiently strong to ensure manufacturer compliance. At the present time manufacturers have been highly cooperative with NIOSH where stop sale requests have been made. However, it must be anticipated that if NIOSH develops new operating protocols which place more responsibility on the manufacturer, such cooperation may not be forthcoming to the same extent. The coordination of these regulatory actions may require coordination with OSHA.

Responsibility for Establishing a Communications Network that Reflects User Experience with PPE and HMI

A satisfactory assurance program cannot rely exclusively on the ability of NIOSH to test devices upon their exit from the assembly line, or to randomly sample and test devices and instruments in the field. A system must be developed for feedback of information by the worker, employer, or the public. Information of crucial importance to an assurance program is the frequency and nature of instrument and device fallure in usage. The establishment of such a user reporting system is as important as efforts by NIOSH to sample and test performance of devices in the field. 
A satisfactory assurance program is not devoted to development of direct reading instruments, improved sampling instruments, etc. The private sector is capable of responding to market needs. NIOSH must establish the criteria for such instruments for usage in the safety and health field. The development of devices and instruments meeting these criteria is the responsibility of the private sector. The history of instrument development in the United States points to the sensitivity of the private sector to newly developing markets and opportunities for profitable endeavors. Product development is not a NIOSH responsibility and is not a characteristic of a product assurance program. NIOSH must clearly differentiate between these two different types of programs.

Perhaps the exceptions to the above statement are those cases where OSHA and regulatees exhibit the inability to implement a recommended standard because there are recognized needs in the PPE or HMI areas. Under such conditions NIOSH should perform research to develop such personal protective equipment. 


\section{SECTION V}

A PROPOSED NIOSH PROGRAM FOR PPE AND HMI TESTING AND CERTIFICATION

Institute and Divisional Responsibilities

The NIOSH program that will result in a well-defined system for testing and certification must have a formal organizational structure with the following components:

A. At the Institute Leve1

1. Policies that reflect NIOSH goals, including but not limited to those already established by legislative directive.

2. Legal expertise and support to serve as a resource for implementation of programs under existing NIOSH authorization and to propose defensible new approaches to permit NIOSH to better meet workers' needs. Legal counsel will also serve other components of the Division of Safety Research.

B. At the Division Leve1

1. A management organization that is responsible for developing program objectives based on policy goals. It must include an administrative unit capable of evaluating the technical management of programs.

2. A systems approach that organizes the technical programs of the TCB and integrates all Sections' functions to meet policy goals and program objectives defined at higher organizational levels.

3. Technical management and programs that assure implementation of procedures for testing and certification that have user protection as their primary objective. The nature of hazards and worker experience should be the bases for program development. 
Legal Basis for Extension of Testing and Certification Beyond Specifically Mandated Programs

The administrative and legal requirements for the NIOSH TCB program must be analyzed carefully along with its technical input so that all the strengths are known to the agency before it acts.

NIOSH should extend its existing program of testing and certification to include categories of protective equipment other than coal mine dust sampling devices and respiratory equipment for coal mine atmospheres. However, it is not clear that NIOSH is authorized to extend its T\&C efforts beyond those mandated by existing statutes. An important first step for NIOSH, then, is the legal assessment to extend Institute authority for requiring manufacturer compliance. Section II of this report suggests possible options for extension of NIOSH authority. These options must be examined in greater depth to determine their authority. If it is concluded that these options are not viable, authority for NIOSH must be sought through new enabling legislation. The Director should immediately initiate this legal investigation of options for NIOSH authority in this field.

A cursory review of options and alternatives in the certification field suggest that the following areas be explored:

1. The Consumer Product Safety Act (15 U.S.C. 2063) has a requirement for product certification and labeling. Under that provision, the manufacturers are obligated to certify that the product conforms to all applicable consumer product safety standards and to say which standards apply.

2. The CPS Act also authorizes an Injury Information Clearinghouse to collect and disseminate information on the causes and prevention of injuries and illnesses. That same section (15 U.S.C. 2064) authorizes the Commission to test consumer products and develop test methods and testing devices and to assist public and private organizations in the development of standards and test methods.

3. OSHA has a regulation setting out rules of procedure and criteria for accreditation of testing laboratories

(29 CFR 1907). However, this regulation has never been implemented. The Department of Commerce also may have voluntary accreditation regulations that could be used in the event the certification program is expanded to include outside labs.

The operation of these options, especially the CPSC system, should be evaluated for its applicability to NIOSH.

In addition to investigating other ways of conducting a certification program, it is also important to review ways of making any such program 
work for the users. Some of the methods that seem appropriate are more precise decertification procedures, recall and stop-sale requirements, as well as maintaining lists of, and notification procedures for, users, along with the necessary publicity to make the procedures effective. In setting up either mandatory or voluntary certification procedures and performance criteria, NIOSH should officially incorporate these types of user protection as a condition for certification.

Authorization of Private Laboratories to Test and Certify

With the demands for testing and certification increasing, NIOSH should investigate the use of qualified laboratories to assist in the testing process. Under such a system, NIOSH would selectively validate findings that the certified equipment from these laboratories meet the established criteria. NIOSH would be able to spend more time conducting routine and periodic destructive tests.

An important question relevant to NIOSH authorization of testing and certification activities is whether these laboratories can be protected from liability litigation. Under the existing system a certification program operated by a government facility encounters less risk of litigation than accredited laboratories assigned testing and certification responsibilities. Accredited laboratories would be liable not just for negligence, but also on liability without fault theories. This situation might deter private laboratories from assisting NIOSH. Nevertheless, NIOSH should define the specific extent of this liability. Congress and the Administration are currently analyzing similar issues in regard to matters involving product liability problems associated with industrial accidents.

Performance Criteria and Standards Development

Existing performance criteria and standards for PPE and HMI, defined in 30 CFR Part 11, are in need of revision and redesign to assure the health and safety of workers. In some instances new criteria and standards must be developed, e.g., women's safety shoes. Presently, older ANSI standards criteria are not adequate for certifying the levels of safety required today. A good example is the test method used to judge the acceptability of safety glasses. ANSI calls for a test method which involves the dropping of a heavy weight onto the glass lens at low velocity. Through in-house experimentation, NIOSH has determined that using a heavy weight at low velocity does not duplicate most situations encountered in industry where workers are most often subjected to the impact of smaller missiles projected at higher velocities.

Pre-manufacturing Notification Procedures

Under the present system, no provision exists to produce failure information associated with PPE and HMI. Thus, the buyer and user of this equipment do so without a knowledge of the risk involved. 
Assuming NIOSH authority exists for the request, a manufacturer would be required to notify NIOSH before product manufacture begins. Upon receipt of a pre-manufacture notification, NIOSH would indicate to the manufacturer that he/she bears full responsibility for the performance of the completed product(s). In addition, NIOSH would indicate that a product would be acceptable and certified only after meeting the performance standard. During the pre-manufacture phase of the process, manufacturers would be required to confirm in writing that quality assurance and product reliability have adhered to standards. Also the manufacturer would be required to: demonstrate product hazard and failure analyses to identify failures or potential failures discovered (by test or other means); make provisions to eliminate causes of equipment failures and those potential failures that could not be eliminated or reduced in frequency of occurrence. Whenever it is determined that a product is associated with a failure that cannot be corrected, the manufacturer will assess the failure prior to testing and certification. This procedure will force the manufacturer to exert greater care in the overall design and development of products. This recommendation has precedent. The EPA Toxic Substances Control Act requires a manufacturer to provide information about the safety of its products during pre-manufacture. The law also states that if there are new findings of deleterious effect, these must also be reported.

In addition to the TSCA requirements, other programs for requiring hazard and failure analyses exist. The Department of Defense, in its MIL Std. 882, "System Safety Program Requirements," 1969, revised 1977, requires a contractor to evaluate his system closely during its conceptual design and engineering development phases to identify, through hazard and failure analyses, hazards which must be either eliminated or reduced to acceptable levels. The size and cost of the system would dictate to what level and to what degree of specificity hazard and failure analyses would be required by the Department of Defense.

Once the failure data, along with the manufacturer's recommendations, are communicated to NIOSH, NIOSH will then verify the manufacturer's analyses. In so doing, NIOSH will develop an information bank of hazard and failure information which will be of value in: (1) testing and certifying the manufacturer's products; (2) providing information to users of PPE and HMI; (3) initiating research and development projects on equipment or components in need; and (4) updating existing and developing new performance criteria and standards.

In summary, revised NIOSH procedures for pre-manufacture testing and certification requiring the manufacturer to submit all existing and potential failure information to NIOSH (whether or not it determined that such failures were a threat to life) places NIOSH in position to better assure workers of the integrity of PPE and HMI. A manufacturer who did not provide known failure information to NIOSH would be in a legally indefensible position, especially if such information were vital to preventing death or injury to workers, as well as in a position of ridicule and in jeopardy of impaired product performance. 
Presently, NIOSH assists manufacturers with development of their quality assurance programs and quality control methods and procedures.

NIOSH should deploy its resources to randomly sample products on the market and to test them according to published procedures for performance evaluation based on published and distributed criteria. In this mode of operation NIOSH would be transferring full responsibility to manufacturers to assure (to a high, but as yet undefined standard of performance) the integrity of their products.

In this new alternate approach NIOSH would be saying: "part of the cost of doing business is the development of these procedures, the efficacy of which would be reflected in the results of NIOSH testing of devices in use in the field or ready for delivery." It is not now clear to what extent NIOSH assumes a share of the responsibility for a failed device manufactured under an approved program. This alternate mode of operation would place full responsibility on the manufacturer; all uncertainties of who carries what burden would be removed.

The present system of assisting manufacturers resulted from Federal efforts to stimulate growth of an infant protective equipment industry. In 1978 domestic respirator sales were reportedly $\$ 160$ million. An industry of this size is no longer an infant and does not require assistance for quality assurance (QA). (NIOSH funding of QA is less than $\$ 500,000 /$ year.) Figure 2 indicates the proposed method of NIOSH involvement to assure the quality of devices on the market.

It involves:

1. NIOSH development of criteria and performance tests for products to assure that they perform satisfactorily.

2. Pre-manufacture notification to NIOSH of new products, with all tests performed by the manufacturer to develop and assure product integrity. NIOSH can further test the submitted devices.

3. Field sampling of products in use to assure that recently manufactured or in-usage devices are performing satisfactorily.

\section{$\underline{\text { Research }}$}

NIOSH should undertake research to develop performance criteria and standards for PPE and HMI including development and verification of the detailed tests to determine adherence of products to these criteria and/or standards. In addition, NIOSH should determine user needs for PPE or HMI which are not being satisfied by products on the market, and should undertake suitable product development through research. In this regard, the user information network discussed below should provide NIOSH with 
ก

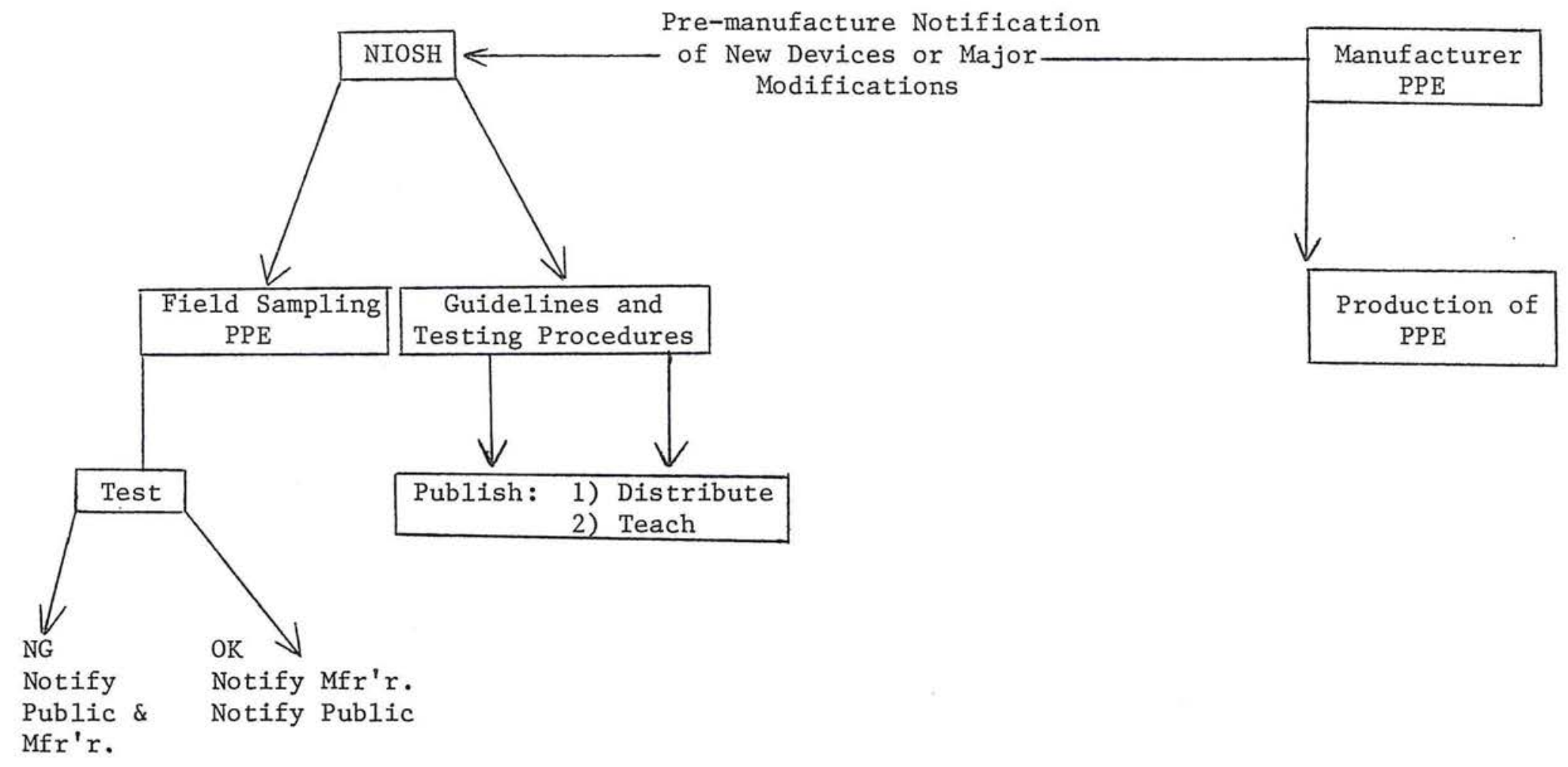

FIGURE 2. PROPOSED NIOSH T\&C PROCEDURES FOR QUALITY ASSURANCE 
great insights into PPE and HMI inadequacies in the field. NIOSH must also coordinate research with OSHA plans to promulgate health and safety standards to insure that the PPE and environmental surveillance provisions of these standards can be implemented.

$\underline{P P E}$ and HMI Field Surveillance System

NIOSH should develop a highly efficient system to acquire and distribute information from users and manufacturers on PPE and HMI malfunctions. We do not underestimate the magnitude of effort required to develop an extensive, easy-to-use, effective information feedback system for these products. However, this is an essential component of an effective testing and certification program.

With regard to manufacturers, NIOSH has already started such a system, "Procedures for Handling Observed or Reported Failures of Certified Products to Meet Applicable Certification Requirements" (November 27, 1978), which is designed to provide manufacturers with failure information ascertained by NIOSH during sampling, examination, and testing or through users' notification. It is recommended that the coverage of this system be expanded to include all manufacturers.

A user reporting system for PPE and HMI malfunctions does not now exist. Information on malfunctions is transferred to NIOSH, apparently, only in extreme failure cases after tragedy or spectacular field malfunctions. The system recommended would have as its goal the reporting of all malfunctions, large or small. 


\section{SECTION VI}

\section{RECOMMENDED NIOSH ACTIONS}

A. The Director of NIOSH should hold a public meeting to solicit views on current testing and certification procedures and proposals for future procedures as presented in this report. A draft of issues has been appended to this report (Appendix B).

B. NIOSH, from the Institute Director's Office, should formulate policy positions that define NIOSH's posture on the testing and certification program. These policies should reflect the assignment of responsibilities proposed in this report.

C. NIOSH should develop a Division of Safety Research program that focuses on TCB areas of responsibility. Components of this plan should include:

1. PPE and HMI performance criteria, standards, and detailed protocols for product testing which reflect the current state of the art.

2. A pre-manufacturing notification and evaluation system aimed at releasing only those products to the market with a high degree of reliability under conditions of field usage.

3. A verification system aimed at sampling products in usage to assure users of continued reliability of manufactured PPE and HMI units.

4. An information feedback system that will provide NIOSH with manufacturer and user product failure and near-failure data and/or experience.

5. An information distribution system that will provide users, potential users, and manufacturers with the quantities of PPE and HMI in use as well as the performance data for them and that have been gathered from the programs outlined in 2,3 , and 4 above.

6. Establishment of a system to certify private laboratories to engage in performance testing of PPE and HMI in accordance with NIOSH verified and published protocols.

7. A research effort aimed at:

a. developing PPE and HMI not on the market and needed to meet present or future OSHA or MSHA

health and safety standards;

b. meeting PPE and HMI needs revealed by programs 2, 3 and 4 above; and 
c. developing and verifying detailed test protocols for performance criteria.

D. Develop in one compendium, a statement of policies, program objectives and activities, responsibilities, test protocols, etc. so that an individual or group such as this consulting group can apprise itself of the Testing and Certification Branch activities without recourse to examination of numerous technical and non-technical publications, statutes, informal notes, and verbal transmittals. This compendium is the analog of a field operations manual. 
APPENDIX A

THE CONSUMER PRODUCT SAFETY ACT

$15 \S 2062$

PRODUCT SAFETY

Ch. 47

stantially in consumer products and (2) as to which there exists a lack of information adequate to determine the safety of such product in use by consumers.

Pub.L. 92-573, § 13, Oct. 27, 1972, 86 Stat. 1219.

\section{Historical Note}

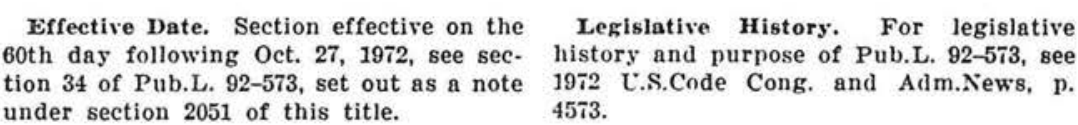

\section{$\S 2063$. Product certification and labeling}

(a) (1) Every manufacturer of a product which is subject to a consumer product safety standard under this chapter and which is distributed in commerce (and the private labeler of such product if it bears a private label) shall issue a certificate which shall certify that such product conforms to all applicable consumer product safety standards, and shall specify any standard which is applicable. Such certificate shall accompany the product or shall otherwise be furnished to any distributor or retailer to whom the product is delivered. Any certificate under this subsection shall be based on a test of each product or upon a reasonable testing program; shall state the name of the manufacturer or private labeler issuing the certificate; and shall include the date and place of manufacture.

(2) In the case of a consumer product for which there is more than one manufacturer or more than one private labeler, the Commission may by rule designate one or more of such manufacturers or one or more of such private labelers (as the case may be) as the persons who shall issue the certificate required by paragraph (1) of this subsection, and may exempt all other manufacturers of such product or all other private labelers of the product (as the case may be) from the requirement under paragraph (1) to issue a certificate with respect to such product.

(b) The Commission may by rule prescribe reasonable testing programs for consumer products which are subject to consumer product safety standards under this chapter and for which a certificate is required under subsection (a) of this section. Any test or testing program on the basis of which a certificate is issued under subsection (a) of this section may, at the option of the person required to certify the product, be conducted by an independent third party qualified to perform such tests or testing programs.

(c) The Commission may by rule require the use and prescribe the form and content of labels which contain the following information (or that portion of it specified in the rule)-

(1) The date and place of manufacture of any consumer product. 
(2) A suitable identification of the manufacturer of the consumer product, unless the product bears a private label in which case it shall identify the private labeler and shall also contain a code mark which will permit the seller of such product to identify the manufacturer thereof to the purchaser upon his request.

(3) In the case of a consumer product subject to a consumer product safety rule, a certification that the product meets all applicable consumer product safety standards and a specification of the standards which are applicable.

Such labels, where practicable, may be required by the Commission to be permanently marked on or affixed to any such consumer product. The Commission may, in appropriate cases, permit information required under paragraphs (1) and (2) of this subsection to be coded.

Pub.L. 92-573, § 14, Oct. 27, 1972, 86 Stat. 1220.

\section{Historical Note}

Effective Date. Section effective on the Legislative History. For legislative 60th day following Oct. 27,1972 , see sec- history and purpose of Pub.L. 92-573, see tion 34 of Pub.L. $92-5 i 3$, set out as a note $19 i 2$ V.S.Code Cong. and Adm.News, p. under section 2051 of this title. 4573 .

\section{$\S 2064$. Substantial product hazards-Definition}

(a) For purposes of this section, the term "substantial product hazard" means-

(1) a failure to comply with an applicable consumer product safety rule which creates a substantial risk of injury to the public, or

(2) a product defect which (because of the pattern of defect, the number of defective products distributed in commerce, the severity of the risk, or otherwise) creates a substantial risk of injury to the public.

Noncompliance with applicable consumer product safety rules; product defects; notice to Commission by manufacturer, distributor, or retaller

(b) Every manufacturer of a consumer product distributed in commerce, and every distributor and retailer of such product, who obtains information which reasonably supports the conclusion that such product-

(1) fails to comply with an applicable consumer product safety rule; or

(2) contains a defect which could create a substantial product hazard described in subsection (a) (2) of this section,

shall immediately inform the Commission of such failure to comply or of such defect, unless such manufacturer, distributor, or retailer has actual knowledge that the Commission has been adequately informed of such defect or failure to comply. 
Public notice of defect or lallure to comply; mall notice

(c) If the Commission determines (after affording interested persons, including consumers and consumer organizations, an opportunity for a hearing in accordance with subsection (f) of this section) that a product distributed in commerce presents a substantial product hazard and that notification is required in order to adequately protect the public from such substantial product hazard, the Commission may order the manufacturer or any distributor or retailer of the product to take any one or more of the following actions:

(1) To give public notice of the defect or failure to comply.

(2) To mail notice to each person who is a manufacturer, distributor, or retailer of such product.

(3) To mail notice to every person to whom the person required to give notice knows such product was delivered or sold.

Any such order shall specify the form and content of any notice required to be given under such order.

Repalr; replacement; refunds; action plan

(d) If the Commission determines (after affording interested parties, including consumers and consumer organizations, an opportunity for a hearing in accordance with subsection ( $f$ ) of this section) that a product distributed in commerce presents a substantial product hazard and that action under this subsection is in the public interest, it may order the manufacturer or any distributor or retailer of such product to take whichever of the following actions the person to whom the order is directed elects:

(1) To bring such product into conformity with the requirements of the applicable consumer product safety rule or to repair the defect in such product.

(2) To replace such product with a like or equivalent product which complies with the applicable consumer product safety rule or which does not contain the defect.

(3) To refund the purchase price of such product (less a reasonable allowance for use, if such product has been in the possession of a consumer for one year or more (A) at the time of public notice under subsection (c) of this section, or (B) at the time the consumer receives actual notice of the defect or noncompliance, whichever first occurs).

An order under this subsection may also require the person to whom it applies to submit a plan, satisfactory to the Commission, for taking action under whichever of the preceding paragraphs of this subsection under which such person has elected to act. The Commission shall specify in the order the persons to whom refunds must be made if the person to whom the order is directed elects to take the action de- 
scribed in paragraph (3). If an order under this subsection is directed to more than one person, the Commission shall specify which person has the election under this subsection.

\section{Relmbursement}

(e) (1) No charge shall be made to any person (other than a manufacturer, distributor, or retailer) who avails himself of any remedy provided under an order issued under subsection (d) of this section, and the person subject to the order shall reimburse each person (other than a manufacturer, distributor, or retailer) who is entitled to such a remedy for any reasonable and foreseeable expenses incurred by such person in availing himself of such remedy.

(2) An order issued under subsection (c) or (d) of this section with respect to a product may require any person who is a manufacturer, distributor, or retailer of the product to reimburse any other person who is a manufacturer, distributor, or retailer of such product for such other person's expenses in connection with carrying out the order, if the Commission determines such reimbursement to be in the public interest.

\section{Hearing}

(f) Án order under subsection (c) or (d) of this section may be issued only after an opportunity for a hearing in accordance with section 554 of Title 5, except that, if the Commission determines that any person who wishes to participate in such hearing is a part of a class of participants who share an identity of interest, the Commission may limit such person's participation in such hearing to participation through a single representative designated by such class (or by the Commission if such class fails to designate such a representative).

Pub.L. 92-573, § 15, Oct. 27, 1972, 86 Stat. 1221.

\section{Historical Note}

Effective Date. Section effective on the 60th day following Oct. $2 \overline{7}, 1972$, see section 34 of Pub.L. 92-573, set out as a note under section 2051 of this title.

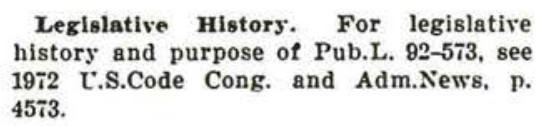
history and purpose of Pub.L. 92-573, see 1972 C.S.Code Cong. and Adm.News, p. 4573.

\section{$\S 2065$. Inspection and recordkeeping}

(a) For purposes of implementing this chapter, or rules or orders prescribed under this chapter, officers or employees duly designated by the Commission, upon presenting appropriate credentials and a written notice from the Commission to the owner, operator, or agent in charge, are authorized-

(1) to enter, at reasonable times, (A) any factory, warehouse, or establishment in which consumer products are manufactured or held, in connection with distribution in commerce, or (B) any con- 
5. Matters considered

The manner in which Commission has acted in promulgating a safety standari is important in judicial review, not only because certain statutory procedural rules apply, but also because commission procedure nbove and beyond those rules has a vital influence on judicial weighing of reeoril facts. Aqua Slide $N$ live Corp. v. Consumer Product Safety Commission,
C.A.5, 1978,569 F.2d 831 . $A$ bias in favor of information exposed to comment is particularly appropriate in standard promulgated under this chapter hecause Congress intended this chapter to maximize public participation. Id.

6. Substantial evidence

In judicial review of a safety standar promulgated uncler this chapter, afte taking procedure into account and weigh ing the evidence, the court must deter mine whether the estahlished facts rea sonably satisfy the criteria necessary t supnort the ultimate statutory finding and if they do, the Commission has sus tained its burden of adducing substantial evidence on the record as a whole for its
finding. Aqun Slite " $"$ " Dive Corp. v.

\section{\$ 2061. Imminent hazards}

\section{Index to Notes}

Collateral estoppel 2

Jurisdiction 1

1. Jurisdiction

Aluminum home wiring systems are "consumer products" within meaning of provision of this chapter giving Commis sion jurisdiction to proceed against hazardous consumer product. Consumer Product Safety Commission v. Anaconda Co., I.C.1).C.1977, 445 F.Supp. $4 ! 98$.

2. Collateral estoppel

P'rior district court decision concluding that aluminum home wiring systems were not "consumer products"
Consumer Product Safety Commission. C.A.5, 1978, 569 F.2d 831 .

7. Walver of right to revlew

Challenge of association, which falled to file petition for review within 60 days after promulgation of consumer protuct atandard governing varinus archi. glazing materials including amiated glass, had to be dismissed. Laminntors Safety Glass Ass'n r. Consumer Product Safety Com'n, 1978, 578 F.
2d 406, 188 U.S.App.D.C. 164. d 406, 188 C.S.App...C. 164.

Swimming pool slide manufacturer's vritten comment to Commission that pro. "ill conceived and not acked un by a sulistantial technical ra. tionale and economic information" or "minimal testing" were sufficient to incorm the Commission of the manufactur. er's basic position and thus the manufac. turer did not waive its right to ruise on judicial review questions concerning the wadicial review questions concerning the present them full to the Commission present them fully to the comnission and did not particinate in the oral hearing. Aqua Slide ' $\mathrm{N}$ ' Dive Corp. Y. Con569 l.2d 831 .

§ 2064. Substantial product hazards

[See main volume for text of (a) to (c)]

Repalr; replacement; refunds; action plan

(d) If the Commission determines (after affording interested parties, including consumers and consumer organizations, an opportunity for a hearing in accordance with subsection (f) of this section) that a product distributed in commerce presents a substantial product hazard and that action under this subsection is in the public interest, it may order the manufacturer or any distributor or retaller of such product to take whichever of the following actions the person to whom the order is directed elects:

[See main volume for text of (1) to (S)]

An order under this subsection may also require the person to whom it applies to submit a plan, satisfactory to the Commission, for taking action under whichever of the preceding paragraphs of this subsection under which such person has elected to act. The Commission shall specify in the order the persons to whom refunds must be made if the person to whom the order is directed elects to take the action described in paragraph (3). If an order under this subsection is directed to more than one person, the Commission shall specify which person has the election under this subsection. An order under this subsection may prohibit the person to whom it applies from manufacturing for sale, offering for sale, distributing in commerce, or importing into the customs territory of the United States (as defined in general headnote 2 to the Tariff Sched- 


\section{$15 \S 2064$ COMMERCE AND TRADE}

ules of the United States), or from doing any combination of such actions, the product with respect to which the order was issued.

[See main volume for text of $(c)$ and $(f)$ ]

\section{Prellminary injanction}

(g) (1) If the Commission has initiated a proceeding under this section for the issuance of an order under subsection (d) of this section with respect to a product which the Commission has reason to belleve presents a substantial product hazard, the Commission (without regard to section 2076 (b) (7) of this title) or the Attorney General may, in accordance with section 2061 (e)(1) of this title, apply to a district court of the United States for the issuance of a preliminary injunction to restrain the distribution in commerce of such product pending the completion of such proceeding. If such a preliminary injunction has been issued, the Commission (or the Attorney General if the preliminary injunction was issued upon an application of the Attorney General) may apply to the issuing court for extensions of such preliminary injunction.

(2) Any preliminary injunction, and any extension of a preliminary infunction, issued under this subsection with respect to a product shall be in effect for such period as the issuing court prescribes not to exceed a period which extends beyond the thirtieth day from the date of the issuance of the preliminary injunction (or, in the case of a preliminary injunction which has been extended, the date of its extension) or the date of the completion or termination of the proceeding under this section respecting such product, whichever date occurs first.

(3) The amount in controversy requirement of section 1331 of Title 28 , does not apply with respect to the jurisdiction of a district court of the United States to issue or exend 1 a preliminary injunction under this subsection.

As amended Pub.L. 94-284, \& 12 (a), May 11, 1976, 90 Stat. 508.

1 So in original. Probably should read "extend".

Reference In Text. Tariff Schedules distributing in commerce, or importing of the T'nited States, referred to in sub. Into the customs territory of the United sec. (d), are set out in section 1202 of States, the product for which the order Title 19, Customs Duties.

94-284, 12(a) (1). provided, in the provi: nidied subsec. (g) sion following par. (3), that an order Lekislative History. For legislative issued under this subsection may pro- history and purpose of Pul.L. O4.284, see hitit the person to whom it applles from 1976 L'.S.Code Cong. and Adm. News, $p$. manufacturing for sale, offering for sale,

$\$ 2067$. Exemption of exports-Risk of injury to consumers within Cnited States

(a) This chapter shall not apply to any consumer product if (1) it can be shown that such product is manufactured, sold, or held for sale for export from the United States (or that such product was imported for export), unless (A) such consumer product is in fact distributed in commerce for use in the United States, or (B) the Commission determines that exportation of such product presents an unreasonable risk of injury to consumers within the United States, and (2) such consumer product when distributed in commerce, or any container in which it is enclosed when so distributed, bears a stamp or label stating that such consumer product is intended for export; except that this chapter shall apply to any consumer product manufactured for sale, offered for sale, or sold for shipment to any installation of the United States located outside of the United States.

Statement of exportation: fillng period, Information; notification of foreign country! petition for minlmum filing period: good cause

(b) Not less than thirty days before any person exports to a foreign country any product-

(1) which is not in conformity with an applicable consumer product safety standard in effect under this chapter, or

(2) which is declared to be a banned hazardous substance by a rule promulgated under section 2058 of this title, 


\section{APPENDIX B}

SUGGESTED ANNOUNCEMENT FOR SOLICITATION OF PUBLIC VIEWS ON THE NIOSH ROLE IN TESTING AND CERTIFICATION OF PPE \& HMI

$\mathrm{NIOSH}$ is in the process of reviewing its current activities in testing and certification of Personal Protective Equipment (PPE) and of Hazard Measuring Instruments (HMI). In this regard, NIOSH hereby solicits the views of all interested parties in development of a more effective program to provide a high degree of product assurance to the user. NIOSH is interested in allocating its resources so that PPE and HMI available to users perform as manufacturers indicate, and that the performance criteria for these devices are at a level of accuracy and reliability consistent with the current state of the art. Specifically, the public is asked to address the following questions:

1. Should NIOSH develop performance criteria for HMI and PPE? If so, what should be the specific priorities for such development?

2. Should NIOSH publish detailed procedures for performance tests to be utilized in establishing adherence to performance criteria for PPE and HMI? Where such tests are now in existence (for example, Title 30 CFR, Part 11) should they be retained or modified?

3. Should NIOSH publish only performance criteria and leave the development of appropriate detailed performance tests to the private sector?

4. Should NIOSH participate on consensus standard making committees such as those of the American National Standards Institute?

5. Should NIOSH offer to manufacturers, on a fee-for-service basis, testing of devices prior to marketing and/or on a continuing basis? In this regard, should NIOSH approve or certify such devices when they pass performance tests developed to assure adherence to performance criteria?

6. Alternately, should NIOSH impose the responsibility for performance testing according to NIOSH developed performance criteria upon manufacturers of PPE and HMI? Should NIOSH monitor manufacturer compliance with performance testing to assure a high degree of reliability of manufacturer PPE and HMI? Should NIOSH coordinate with OSHA such assurance of manufacturer adherence to performance testing protocols?

7. Should NIOSH develop a system of random sampling of PPE and HMI on the market, evaluate them for reliability using appropriate performance tests, and widely distribute the results of testing? Or should NIOSH undertake to contract such sampling and testing of products on the market? 
8. If NIOSH contracts for services described in (6\&7), should laboratories be certified by NIOSH to perform these tasks?

9. Should there be a scheduled recertification procedure? If so, at what intervals of time?

10. Should NIOSH certify private laboratories for testing of PPE and HMI in accordance with published NIOSH performance criteria and tests? These laboratories could perform tests for manufacturers or purchasers of PPE and HMI.

11. Should NIOSH continue to offer assistance to manufacturers with the establishment of facilities and tests for PPE and HMI in accordance with NIOSH performance criteria and tests? Should NIOSH continue to evaluate test setups at manufacturers' facilities?

12. Should NIOSH undertake to develop a reporting system by which all failures of PPE and HMI in the field are reported to NIOSH for subsequent alerting of the public and the manufacturer? What are the essential components of such a system?

13. Should NIOSH undertake to widely publicize results of tests performed on PPE and HMI products randomly sampled from the marketplace or from manufacturer assembly lines?

14. Should NIOSH continue to require manufacturers' submission of all changes or alterations in manufactured products which previously met NIOSH performance tests? Alternately, should manufacturers retain all such records?

15. What should be the recall or "stop sale" obligations of NIOSH and manufacturers when HMI or PPE in the field are found to be defective?

16. What should be the public notification mechanisms upon discovery of defective PPE or HMI in the field?

17. Should NIOSH undertake research to develop needed HMI and PPE in general? Or should NIOSH undertake to perform research for new PPE and HMI only insofar as they are required for OSHA or MSHA proposed or existing standards implementation?

18. What should be the role of NIOSH in sponsoring research on needed PPE and HMI? What is the interval of time from promulgation of performance criteria for needed PPE and HMI to the undertaking of development research for product development by NIOSH. In other words, when should NIOSH acknowledge the failure of market forces to bring forth needed HMI or PPE and undertake their development? 
NIOSH Publication, "A Workers' Guide to NIOSH," October, 1978.

Annual Report - 1978, Executive Summary, Division of Safety Research.

C. Division of Safety Research Reports, Memoranda, etc.

"NIOSH Strategy for Providing More Effective Hazard Measuring Instruments and Personal Protective Equipment,"

January 9, 1979.

"Tests of Self-Contained Breathing Apparatus Received from Lubbock, Texas, Fire Department," June, 1979.

"Chronology of 1979 NIOSH Actions Regarding Problems with Scott SCBA Respirators," August 22, 1979, requested by the consultants.

Memo, Subject: "NIOSH Involvement in Hazard Measuring Instruments Evaluations," to DSR, TCB Consultants from Chief, Air Sampling Instruments, TCB, July 10, 1979.

Memo, Subject: "NIOSH Certification of Gas Detector Tube Units (GDTUs)," to the Director of NIOSH from the Director of DSR, July 2, 1979.

Memo, Subject: "Respirator Research Summary Per Request of TCB Consultants," from Research Industrial Engineer, August 17, 1979 .

A compilation of materials that represents a guide for the Respirator Section during testing and certification of a product, from Richard Ronk at the request of the consultants, August, 1979.

Respirator Section, "Tentative Projects for FY80."

Physical Agents Section, "Tentative Projects for FY80."

Quality Assurance Section, "Procedures and Checklists for Preparation of Quality Control Plans and Manuals, Rev. 2, $1 / 28 / 76 . "$

NIOSH Project Plan, "Air Sampling Instruments Testing and Certification," 9/13/77, 9/13/78.

Draft Proposal, "NIOSH Certification Requirements for Gas Detector Tube Units," M. M. Roder, 7/10/79.

Letters to all manufacturers of NIOSH certified products from DSR, "Procedures for Handling Observed or Reported Failures of Certified Products to Meet Applicable Certification Requirements," November 27, 1978. 
Interagency Agreement between NIOSH and ERDA (now the DOE) for Respirator Test Method Development, "Respirator Studies for the National Institute for Occupational Safety and Health," Los Alamos Scientific Laboratory of the University of California, Los Alamos, New Mexico, 1972 through 1977.

D. Public Comments and Articles

NIOSH Respirator Users Warning to Scott Air Supply Respiratory Products Distributors, May 3, 1979.

"Fire Fighters Contend NIOSH-Approved Respirator Standards Inadequate," Occupational Health \& Safety Letter, May 22, 1979.

"IAFF Critical of NIOSH Over Breathing Apparatus," IAFF, June, 1979.

Statement by Dr. Anthony Robbins at Safety Expo 79, "NIOSH Reassesses Testing and Certification Program," June 28, 1979.

Statement by Dr. Anthony Robbins before the Federal Trade Commission, Washington, D. C., "Our Experience in Evaluating the Performance of Industrial Protective Equipment Against Standards Devised by Consensus Organizations," July 26, 1979.

E. Statutes, Regulations, Federal Register Notices, etc.

Federal Mine Safety and Health Amendments Act of 1977, 30 U.S.C. 801, Public Law 95-164, 95th Congress, November 9, 1977.

Occupational Safety and Health Act of 1970, 29 U.S.C. 651, Public Law 91-596, 91st Congress, December 29, 1970.

Department of the Interior, Bureau of Mines, "Procedures for Establishing a List of Permissible Self-Contained Mine Rescue Breathing Apparatus," Schedule 13, March 5, 1919.

Code of Federal Regulations: Title 30, Parts 11, 70, 74; Title 42, Parts 82, 84 .

Federal Register Notice by the Public Health Service, CDC, "Statement of Organization, Functions and Delegation of Authority," Vo1. 42, No. 114, Tuesday, June 14, 1977.

Federal Register Notice by the Mine Safety and Health Administration, "Respiratory Protective Apparatus; Tests for Permissibility; Fees," Vo1. 44, No. 112, Friday, June 8, 1979. 
A. Personal Interviews and Discussions

Office of the Director

Dr. Anthony B. Robbins, Director of NIOSH

$\underline{\text { Division of Safety Research Personnel }}$

Dr. James A. Oppold, Director

Dr. Nick Blaskovich, Division Liaison with the Consultants

Dr. Alan Stevens, Acting Branch Chief, Testing and Certification

Dr. Donald Campbell, Safety Equipment Section, TCB

Mr. Richard Ronk, Respirator Section, TCB

Mr. Samuel Terry, Respirator Section, TCB

Mr. Alwin Dieffenbach, Physical Agents Section, TCB

Mr. Michael Roder, Air Sampling Instruments Section, TCB

Mr. Howard Swartz, Quality Assurance Section, TCB

Mr. Robert Schutz, Former Branch Chief, TCB

Others

Mr. Larry Reed, Respirator Research, NIOSH, Cincinnati

Mr. Stanley Reno, Regional Consultant, Denver

Dr. Walter Ruch, Regional Consultant, Seattle

Dr. Nelson Leidel, NIOSH, Rockville

\section{B. NIOSH Reports}

Technical Report, "Impact Performance of Safety Eyecup Goggles," July, 1979.

Technical Report, "A Guide to Industrial Respiratory Protection," June, 1976.

Technical Report, "A Report on the Performance of Personal Noise Dosimeters," September, 1978.

Technical Information, "Tests of Eyecup Goggles," May, 1977.

Technical Information, "A Report on the Performance of Firefighters' Helmets," July, 1976.

Technical Information, "Women's Safety-Toe Footwear," July, 1976.

NIOSH Report, "NIOSH Certified Equipment List as of July 1, 1978," November, 1978. 
Richard Brief is the Director of the Industrial Hygiene Research and Environmental Health Division of Exxon Corporation, P.0. Box 45, Linden, New Jersey 07036.

Morton Corn is Professor of Occupational Health, Graduate School of Public Health, University of Pittsburgh and President of Morton Corn and Associates, Environmental Consultants and Engineers for Occupational Health, Industrial Hygiene, Safety Science and Air Pollution, 310 Bower Hill Road, Pittsburgh, Pennsylvania 15228,

Robert Firenze is President of RJF Associates, Occupational and Environmental Affairs Consultants for Occupational \& Public Safety \& Health Programs, Construction Safety Engineering, Education \& Training Program Design, Educational Materials Development, Program Evaluation and Energy Conservation Research, P.0. Box 1428, Bloomington, Indiana 47401.

Mary-Win O'Brien is Assistant General Counsel for the United Steelworkers of America, 5 Gateway Center, Pittsburgh, Pennsylvania 15221.

David Scott is an Independent Consultant for Occupational Health and Safety Programs, and Occupational and Environmental Health and Safety Programs related to Nuclear Fuel Cycle Facilities, R.D. 1, Rochester, Vermont 05757. 

DEPARTMENT OF

HEALTH, EDUCATION, AND WELFARE PUBLIC HEALTH SERVICE

CENTER FOR DISEASE CONTROL

NATIONAL INSTITUTE FOR OCCUPATIONAL SAFETY AND HEALTH ROBERT A. TAFT LABJRATORIES

THIRD-CLASS

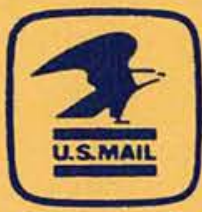

4676 COLUMBIA PARKWAY. CINCINNATI. OHIO 45226

POSTAGE AND FEES PAIO

U.S. DEPARTMENT OF H.E.W

OFFICIAL BUSINESS

HEW 396

PENALTY FOR PRIVATE USE. $\$ 300$ 